\title{
Synthesis, spectral characterization and DFT calculations of novel macro MADIX agent: mechanism of addition-fragmentation reaction of xanthate compound
}

\author{
Ümit Yildiko ${ }^{1}$ - Ahmet Cagri Ata ${ }^{2}$ (D) I İsmail Cakmak ${ }^{2}$
}

Received: 2 June 2020 / Accepted: 3 September 2020 / Published online: 12 September 2020

(c) Springer Nature Switzerland AG 2020

\begin{abstract}
In this study, the macromolecular design was performed via interchange of xanthates (MADIX) polymerization. The macro RAFT/MADIX agent containing the structure of polytetrahydrofuran (PTHF) (average $\mathrm{Mn} \sim 1000 \mathrm{~g} / \mathrm{mol}$ ) was synthesized to use in the polymerization. PS-b-PTHF-b-PS triblock copolymer was obtained by styrene-controlled radical polymerization using the RAFT/MADIX agent. The plot of $\ln [\mathrm{M}]_{\mathrm{O}} /[\mathrm{M}]$ versus monomer concentration versus polymerization time exhibits first-order kinetic behavior. Block copolymer formation has a controlled character. The formation of the narrow molecular weight polymer controlled by the styrene's RAFT/MADIX polymerization is confirmed by the increase in the polymerization time of the molecular weight. The results are in good agreement with theoretical values. Block copolymers having a narrow molecular weight distribution and a predetermined average molecular weight have been obtained using this polymerization process. The synthesized RAFT/MADIX agents, polymer, and copolymers were characterized by NMR and FT-IR spectroscopy, GPC, and differential scanning calorimetry. Based on the vibration analysis, the thermodynamic properties of the compound were also calculated. Optimized structure, frontier molecular orbitals (HOMO and LUMO) and global reactivity descriptors were analyzed by DFT calculations. As a result of the DFT study with trimer and hexamer; although the chain length is increased, the energy parameters obtained are very proximate to each other.
\end{abstract}

Keywords MADIX polymerization · Block copolymer - PTHF · DFT · NBO

\section{Introduction}

The synthesis of various types of macromolecules, including block copolymers, is usually obtained by reversible-deactivation radical polymerization [1]. In recent years, significant developments have occurred in the synthesis chemistry, such as the ability to obtain innovative polymeric materials $[2,3]$, by controlling molecular properties $[4,5]$, chain length distribution, stereogenicity, copolymer composition, block copolymer alignment, lengths and functional group addition [6-11]. Controlled/living radical polymerization (CRP) are known as living polymerization techniques [12-14]. The CRP mechanisms consist of different polymerization mechanisms which are used to obtain polymers with controlled molecular weight growth and a narrow molecular weight distribution [15-19]. The most commonly used CRP techniques are nitroxide mediated radical polymerization (NMP) [20-22], atom transfer radical polymerization (ATRP) $[6,23,24]$, reversible addition-fragmentation chain transfer (RAFT), and macromolecular design via interchange of

Electronic supplementary material The online version of this article (https://doi.org/10.1007/s42452-020-03495-3) contains supplementary material, which is available to authorized users.

Ümit Yildiko, yildiko1@gmail.com | ${ }^{1}$ Architecture and Engineering Faculty, Department of Bioengineering, Kafkas University, Central Campus, 36100 Kars, Turkey. ${ }^{2}$ Faculty of Arts and Sciences, Department of Chemistry, Kafkas University, 36100 Kars, Turkey. 
xanthates (MADIX) polymerizations [25-30]. More distinct and specific results are obtained by combining CRP mechanisms with certain other processes [31, 32]. DFT allows the approximate inclusion of electron correlation at a lower computational cost compared to traditional linked ab initio methods such as Møller-Plesset perturbation theory, configuration interaction, and combined set theory. For large molecules, it is now widely accepted that density functional theory provides a valuable and in some cases the only alternative to obtain accurate values for these criteria. B3LYP method provides a good balance between placed and localized bond structures. However, the improvements are not systematic and better results are obtained at the MP2 level, but there are some well-known examples such as the ${ }^{13} \mathrm{C}$ chemical shift case on $\sigma$-benzyne where HF and MP2 failed and DFT performed well. Other studies are indicating the usefulness of DFT methods. Recently, the performance of DFT methods in the calculation of NMR properties has also been the subject of many theoretical studies [33]. The semiempirical PM6 method was used to calculate the geometric structures of the selected polymeric macro RAFT/MADIX agent and the density functional theory (DFT) [34-36] based on the level of B3LYP/6-31G (d, p) was used in the calculation of the HOMO-LUMO energy gaps [37-41]. There is a good agreement between the accuracy of the DFT method used and the calculation time required in many studies. The calculated band gaps in the two available oligomers were compared. Next, the reliability of the given methodology to estimate the polymer structure of the studied compound was evaluated. Here, the main purpose of our DFT study is to determine the properties of the polymeric structure over small molecule groups.

In this work, we presented RAFT/MADIX agent design and its usage in controlled radical polymerization. According to our best knowledge, this is the first type of block copolymer which was prepared by polymerization with poly (tetrahydrofuran) (PTHF) macro MADIX agent. A number of PS-bPTHF-b-PS triblock copolymers were prepared by CRP, and a direct comparison of reaction kinetics was used. Also, in this paper the analysis of the highest occupied molecular orbital (HOMO) and the lowest unoccupied molecular orbital (LUMO) energies, the molecular electrostatic potential (MEP) distribution of the molecule, the natural bond orbital (NBO) analysis were used to explain the interaction between electron donors and receptors, as well as the Mulliken population analysis of atomic charges of various molecular atoms.

\section{Experimental}

\subsection{Materials}

Poly tetrahydrofuran (PTHF) (average $\mathrm{Mn} \sim 1000 \mathrm{~g} / \mathrm{mol}$, 99\% Sigma-Aldrich), carbon disulfide ( $\left.\mathrm{CS}_{2}\right)$ 99\% Merck), potassium hydroxide (KOH) $85 \%$ Sigma-Aldrich), benzoyl chloride $\left(\mathrm{C}_{6} \mathrm{H}_{5} \mathrm{COCl}\right)$ (99\% Sigma Benzyl (Aldrich) is a product of Styrene (St) (Sigma-Aldrich). 2,2.-Azobis (isobutyronitrile) (AIBN) (\%99 Sigma-Aldrich) was recrystallized from toluene and stored in a refrigerator. Diethyl ether ( $\sim 99.5 \%$ Riedel-de Haen), Petroleum ether ( $99 \%$ Riedel-de Haen), Sodium sulfate $\left(\mathrm{Na}_{2} \mathrm{SO}_{4}\right)$ (99.5\% Sigma), Methanol $\left(\mathrm{CH}_{3} \mathrm{OH}\right)$ ( 99\% Emboy), Styrene (St) (> 99.0\% Sigma-Aldrich).

Gel Permeation Chromatography (GPC) has been carried out WatersBreeze spectrometer and THF were used as a solvent ( $1 \mathrm{~mL} / \mathrm{min})$. The system was calibrated with polystyrene standards. FT-IR spectra were recorded of the polymer films cast from $\mathrm{CHCl}_{3}$ solutions, using a Bruker Alpha-P spectrometer. NMR spectroscopy was performed in İnönü University. The devices are ${ }^{1} \mathrm{H}-\mathrm{NMR}$ BrukerAvance III HD 600.134 MHz model and ${ }^{13} \mathrm{C}-\mathrm{NMR}$ BrukerAvance III HD $150.918 \mathrm{MHz}$. Differential scanning calorimetry (DSC) analysis has been performed at a heating rate of $10^{\circ} \mathrm{C} \mathrm{min}^{-1}$ in the temperature range of $25-500^{\circ} \mathrm{C}$ under the nitrogen flow of $100 \mathrm{~mL} \mathrm{~min}^{-1}$ simultaneous DSC analyzer using DSC-60 SHIMADZU.

\subsection{Synthesis of polytetrahydrofuran macro xanthate/MADIX agent}

The controlled radical polymerization technique was applied. MADIX agent was used as azo initiator, benzene as a solvent, and styrene as a monomer. $40 \mathrm{~g}$ PTHF and $15 \mathrm{~mL}$ benzene were added into the glass balloon and left under stirring until completely dissolved. After adding $0.08 \mathrm{~mol}$ of $\mathrm{KOH}$ to the solution, the mixture was stirred for $7 \mathrm{~h}$ on a magnetic stirrer. Then, $0.08 \mathrm{~mol}(5 \mathrm{~mL})$ of carbon sulfide $\mathrm{CS}_{2}$ which has a density of $1.21 \mathrm{~g} / \mathrm{cm}^{3}$, was added into the balloon. The mixture was left under reflux with stirring for $18 \mathrm{~h}$ at room temperature. The reaction is given in Scheme 1 . The obtained mixture was added to $0.08 \mathrm{~mol}$ of benzoyl chloride. A yellowish brown color was observed.

The reaction mixture was filtered and the filtrate was evaporated using a rotary vacuum evaporator at $40^{\circ} \mathrm{C}$ for $45 \mathrm{~min}$. The residue was precipitated in a mixture of $50 \%$ diethyl ether-50\% petroleum ether. After waiting 1 day in the freezer, the solvent was decanted. The precipitate was left on the oven (7-8 h). The difunctional 
Scheme 1 Synthesis of PTHF Macro Xanthate/MADIX agent. (Reaction time; $18 \mathrm{~h}$, reaction temperature at room temperature and used compounds; $40 \mathrm{~g}$ PTHF, $15 \mathrm{~mL}$ benzene, $0.08 \mathrm{~mol} \mathrm{KOH}, 0.08 \mathrm{~mol}(5 \mathrm{~mL})$ $\mathrm{CS}_{2}, 0.08$ mol benzoyl chloride)

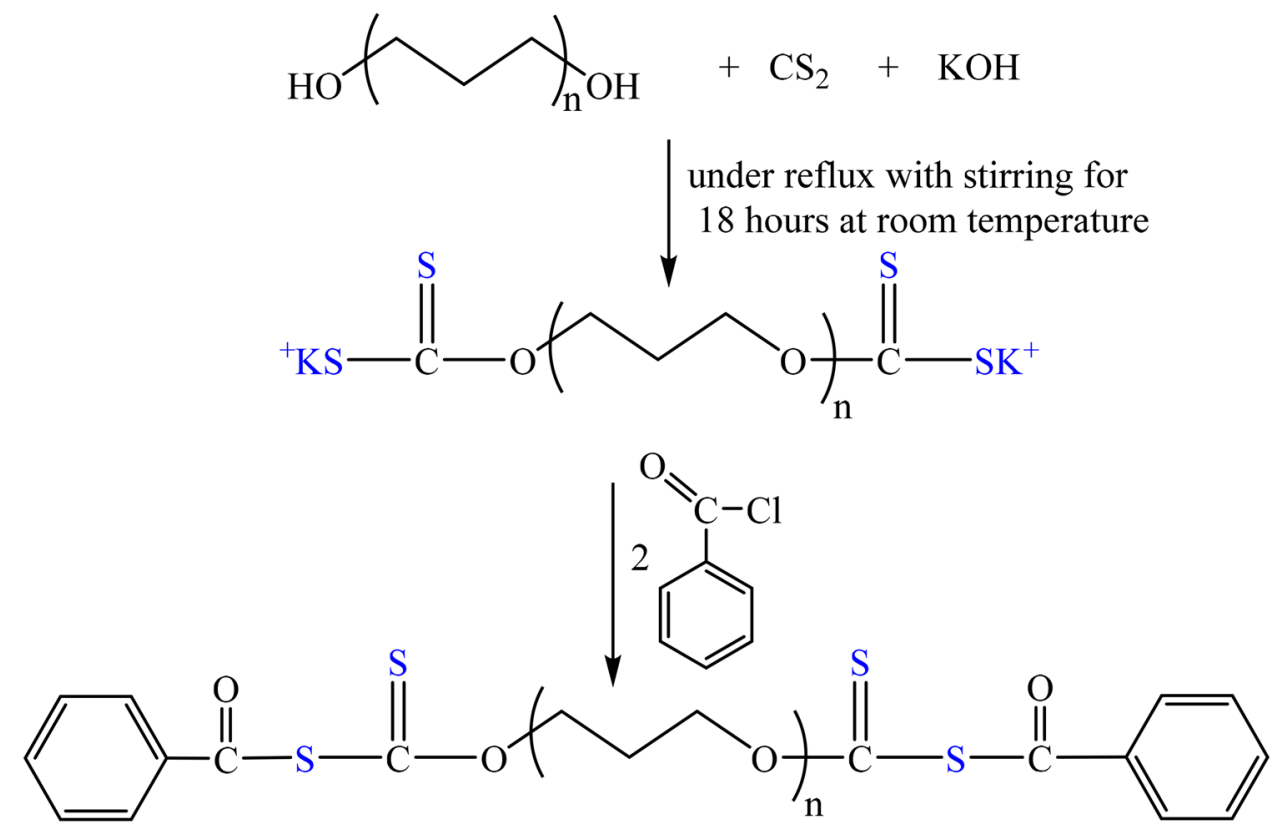

(1)

PTHF Macro Xanthate/MADIX agent

double-ended macro xanthate MADIX agent was dried in a vacuum oven. $46.3 \mathrm{~g}$ of the product was obtained in $85 \%$ yield. The molecular weight of the PTHF Macro Xanthate/MADIX agent is $1362 \mathrm{~g} / \mathrm{mol}$. FT-IR $\left(\mathrm{cm}^{-1}\right): 2937$ $(\mathrm{Ar}-\mathrm{H}), 2852\left(\mathrm{CH}_{2}-\mathrm{CH}_{2}\right), 1721(\mathrm{C}=\mathrm{O}), 1499,1453(\mathrm{Ar})$, 1206 (C=S), 876 (C-S) (Fig. S2). ' H NMR (600.134 MHz, $\mathrm{CDCl}_{3}$ ): $\delta$ (ppm) 7.87-7.16 (m, 5H, aromatic), 3.73-3.33 $\left(\mathrm{m}, 6 \mathrm{H},\left(\mathrm{CH}_{3} \mathrm{CH}_{2} \mathrm{O}\right)\right), 1.73\left(\mathrm{~m}, 2 \mathrm{H},\left(\mathrm{CH}_{2} \mathrm{CH}_{2} \mathrm{CH}_{2}\right)\right), 1.63$ (s, 9H, $\left.\left(\mathrm{OCH}_{2} \mathrm{CH}_{2}\right)\right), 0.66\left(\mathrm{t}, 2 \mathrm{H}, \mathrm{SCH}_{2} \mathrm{CH}_{2}\right)$ (Fig. S4). ${ }^{13} \mathrm{C}$ NMR (150 MHz, CDCl $)_{3}$ : $\delta$ (ppm) $169(\mathrm{C}=\mathrm{S}), 135(\mathrm{C}=\mathrm{O})$, 132-127.69 (aromatic), $69.48\left(-\mathrm{OCH}_{2} \mathrm{CH}_{2}\right), 39.46$ (-SCO), $26.1\left(-\mathrm{CH}_{2} \mathrm{CH}_{2} \mathrm{CH}_{2}\right)$ (Fig. S5).

\subsection{Synthesis of poly(St-b-PTHF-b-St) triblock copolymer}

$0.9384 \mathrm{~g}\left(7 \times 10^{-4} \mathrm{~mol}\right)$ compound 1 was dissolved in $10 \mathrm{~mL}$ benzene and then, $10 \mathrm{~mL}$ styrene was added to the solution. The obtained mixture was divided into $2 \mathrm{~mL}$ solution and stirring bar for per tube. The mixture in the tube was degassed by argon gas. The tube was tightly capped with a rubber septum and was placed into a silicone oil bath which thermostated at $60-65^{\circ} \mathrm{C}$. Reaction was carried out for $5,10,15,20,25,30,40,45$ and $50 \mathrm{~h}$. After the polymerization, poly(St-b-PTHF-b-St) triblock copolymer was isolated in $50-60 \mathrm{~mL}$ methanol. The obtained copolymers were dried under vacuum at room temperature for 2 days to yield a white solid (Scheme 2 ).
The copolymer reaction is given in Fig. 1. FT-IR $\left(\mathrm{cm}^{-1}\right)$ : $2937(\mathrm{Ar}-\mathrm{H}), 2852\left(\mathrm{CH}_{2}-\mathrm{CH}_{2}\right), 1721(\mathrm{C}=\mathrm{O}), 1499,1453(\mathrm{Ar})$, 1206 (C=S), 876 (C-S) (Fig. S3). ${ }^{1} \mathrm{H}$ NMR $(600.134 \mathrm{MHz}$, $\left.\mathrm{CDCl}_{3}\right): \delta$ (ppm) 7.87-7.16 (m, 5H, aromatic), $\delta$ (ppm) 6.87-6.56 m, (Graft-5H, aromatic) 5,2 (m, CH-Ar), 3.73-3.33(m, $\left.6 \mathrm{H},\left(\mathrm{CH}_{3} \mathrm{CH}_{2} \mathrm{O}\right)\right), 1.73\left(\mathrm{~m}, 2 \mathrm{H},\left(\mathrm{CH}_{2} \mathrm{CH}_{2} \mathrm{CH}_{2}\right)\right)$, $1.63\left(\mathrm{~s}, 9 \mathrm{H},\left(\mathrm{OCH}_{2} \mathrm{CH}_{2}\right), 0.11\right.$ (t, $\left.2 \mathrm{H}, \mathrm{SCH}_{2} \mathrm{CH}_{2}\right)$ (Fig. S6).

\section{Results and discussion}

The most important goal of CRP techniques is to produce polymer materials with low heterogeneity index [42]. The narrow molecular weight distribution is the ratio of the molecular weight $\left(M_{w}\right)$ by weight to the molecular weight $\left(M_{n}\right)$ by number $(\Theta<1.1)$. Another conception in the literature is polydispersity (PDI). Our PDI values varied between 1.3 and 1.48 .

The success of polymerization is that the calculated molecular weight is close to the result of GPC analysis. In our studies, a great deal of equivalence was found between $M_{\text {ntheo }}$ and $M_{n G P C}$. The GPC analyzes are given in Fig. 1a. The differences are thought to be caused by reaction conditions, initiator activity and impurities.

Theoretical molecular weights of block copolymers can be calculated according to the following equation [43]: 
<smiles>CCCCOC(=S)C(=S)SC(=O)c1ccccc1</smiles>

(1)<smiles>C=Cc1ccccc1</smiles>

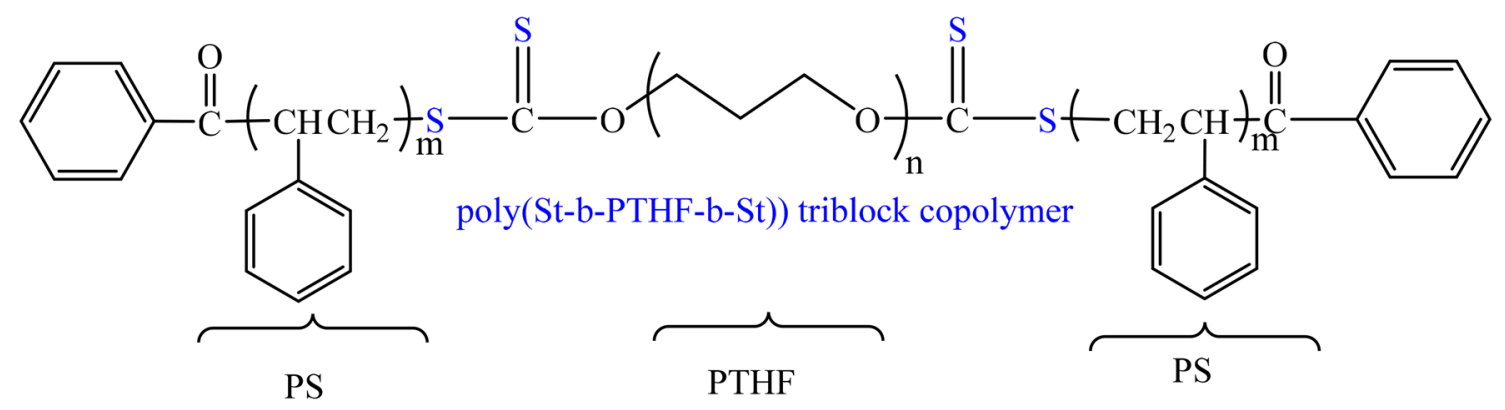

Scheme 2 Synthesis of poly(St-b-PTHF-b-St) triblock copolymer. (Reaction time; 5-50 h, reaction temperature at 60-65 ${ }^{\circ} \mathrm{C}$; MADIX Agent, $10 \mathrm{~mL}$ benzene, $10 \mathrm{~mL}$ styrene)

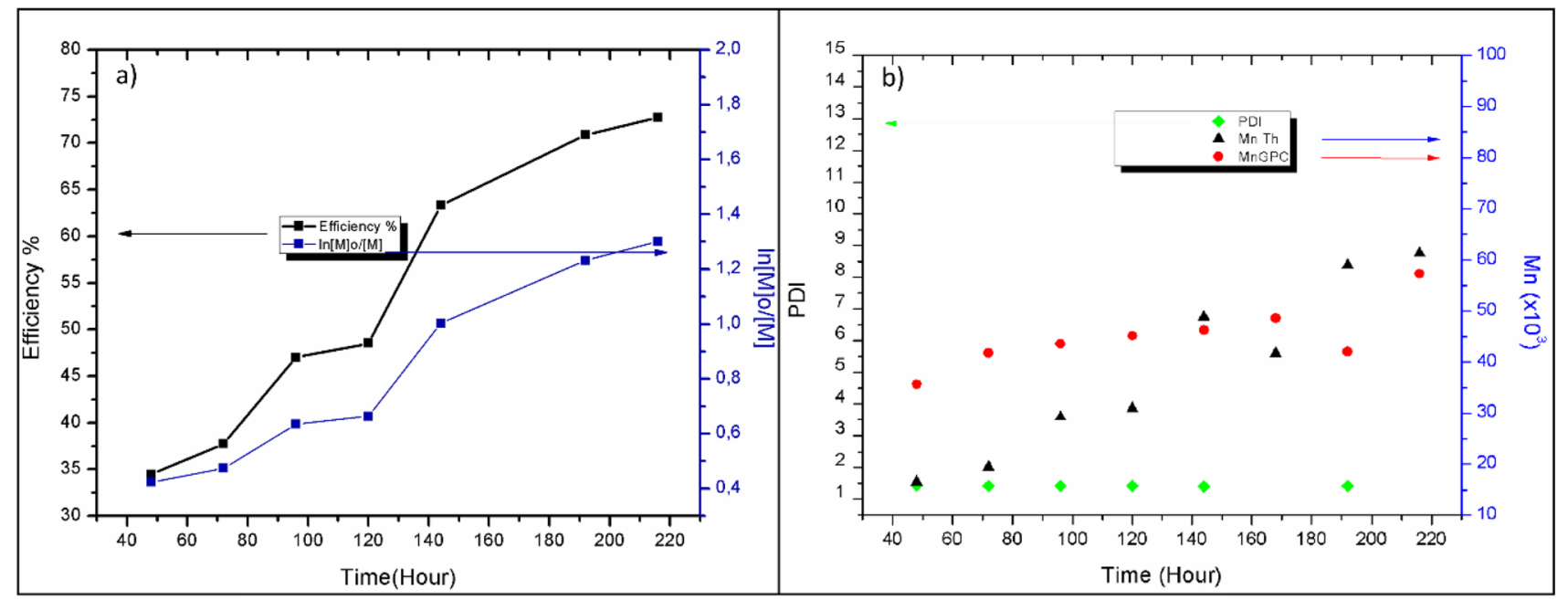

Fig. 1 a $M_{n(\text { Theo-GPC })}-$ PDI-time graph of styrene MADIX polymerization $\mathbf{b} \ln [\mathrm{M}]_{0} /[\mathrm{M}]$ — $\%$ Efficiency —Time graph of MADIX polymerization of styrene

$M n_{(\text {Theo })}=\frac{[M]}{[M C T A]} \times$ Conversion $\times M W_{\text {styrene }}+M W M_{C T A}$

where $[\mathrm{M}]$ is the molar concentration of styrene, [MCTA] is the molar concentration of MCTA, MW styrene is the molecular weight of monomer, and $\mathrm{MWM}_{\mathrm{CTA}}$ is the molecular weight of MCTA. Styrene was polymerized with Polytetrahydrofuran (PTHF) macro MADIX agent (1298 g/ mol). There are two important properties of the synthesized MADIX agent: first it is difunctional and the chain end bears a benzoyl chloride group. The polymerization reaction was carried out with a molar ratio monomer/ MADIXagent/initiator [St]:[XCTA]:[AIBN] = 1000:8:1.6. PSPTHF-PS block copolymers were obtained using a symmetric macro MADIX agent. GPC analyzes of the obtained block copolymers were carried out. PDI-Mn-Time graphics 
were plotted in all polymerization data according to the results obtained from GPC analysis. The GPC analyzes are given in Fig. 1a. Also, Fig. S7, Fig. S8 and Fig. S9 show GPC chromatogram PS-b-PTHF-b-PS triblock copolymers (PTHP5), (PTHP7), and (PTHP9) respectively.

\subsection{Mechanism of the politetrahydrofuran (PTHF) reaction}

The radical active center is formed using azobisisobutyronitrile containing azo initiator groups. The radical source of the reaction occurs in the initiation step. The macro MADIX agent radical is formed by the addition of monomers.

The function of the group- $Z$ allows radical groups to bind easily to the thiocarbonyl $(C=S)$ bond, where $Z$ is the group of PTHF xanthate. The benzoyl group separates to form a radical end. During the first step of the polymerization, the growing radical polymer is added to the thiocarbonylthio $\left[R S C(Z)=S^{\prime}(1)\right]$ compound. Intermediate radical $\mathrm{R}$ and a polymeric thiocarbonylthio compound are obtained.

The leaving group $(-R)$ formed at the end of the reaction enters the reaction with one of the styrene monomers present in the solution medium. Thus, another active polymer chain is formed. The active chain obtained in this step will be subjected to growth-fragmentation and stabilization steps by itself. R-PS occurs as a result of adding the monomer to the new radical $(\mathrm{R})$.

The radical group on the growing macro-MADIX agent and R-PS thiocarbonyl compounds reversibly interact. This reversible reaction forms the equilibrium, the most basic step of polymerization. It is so common in the traditional radical polymerization that chain termination steps do not occur in this system. Rapid equilibrium occurs with the radical group of the active growing macro-MADIX agent and R-PS. At the same time, due to the predominant effect of thiocarbonylthio compounds, it provides equal opportunity for the growth of all chains and the production of narrow molecular weight polymers. Therefore, the styrene monomer was separated from the active growing chains. A block copolymer of PS-PTHF-PS was obtained at the termination step (Scheme 3).

The indication of the completed control of MADIX polymerization is the linear increase of the $M_{n}$-time graph. During the polymerization, the molecular weight increases proportionally to monomer consumption. Also, it is desired that MADIX polymerizations have polydispersity values close to 1 . The reaction data are given in Table 1 .

Considering the green colored marks according to Fig. 1 , it is seen that the PDI values are almost the same in the copolymer reaction. Here they prove that controlled reversible chain transfer has been working since the first growth step. This result shows us that the molecular weight distribution of the polymers obtained by MADIX polymerizations is very narrow. PDI values of 1.21-1.44 obtained as a result of MADIX polymerization are the expected values.

According to Fig. 1a the experimental and theoretical molecular weights of the synthesized copolymers are compatible with each other. During the reaction, the \% efficiency increases linearly. The time-conversion efficiency and time $\ln [\mathrm{M}]_{0} /[\mathrm{M}]$ Fig. $1 \mathrm{~b}$ were plotted using the amounts of synthesized polymer and the values given in Table 1.

The MADIX agent shows $1-2 \mathrm{ppm}-\mathrm{CH}_{2}$ protons, 3.6-5 ppm $-\mathrm{CH}$ protons, and 7.5-8 ppm aromatics $-\mathrm{CH}$ protons in the ${ }^{1} \mathrm{H}-\mathrm{NMR}$ spectra. In the ${ }^{1} \mathrm{H}$-NMR spectra of the block copolymers, the $-\mathrm{CH}_{2}$ protons in the polytetrahydrofuran structure is about at 1-2 ppm, the oxybonded $\mathrm{CH}_{2}$ protons in the polytetrahydrofuran structure is between the 3-3.5 ppm, and the $-\mathrm{CH}$ protons in the aromatic structure are between the 7.5 and $8 \mathrm{ppm} .{ }^{13} \mathrm{C}$ NMR $\left(\mathrm{CDCl}_{3}\right)$ : In the ${ }^{13} \mathrm{C}-\mathrm{NMR}$ spectra of MADIX agent shows $-\mathrm{CH}_{2}$ groups is $23 \mathrm{ppm}$, solvent and $-\mathrm{CH}_{2}$ groups is $40 \mathrm{ppm},-\mathrm{OCH}$ groups is $75 \mathrm{ppm}$, The $-\mathrm{CH}$ groups in the aromatic ring is $130 \mathrm{ppm}$, the $\mathrm{C}=0$ groups is $135 \mathrm{ppm}$, and the $C=S$ groups is $170 \mathrm{ppm}$. Comparison of experimental and theoretical FT-IR spectra of PS-b-PTHF-b-PS triblock copolymers (Fig. S11). Figure S1 shows FT-IR spectrum of PTHF 1000.

The thermal properties of the synthesized polymers are determined by DSC analysis. Temperature transitions in a general DSC analysis of PS-b-PTHF-b-PS were given in Fig. $2 \mathrm{~b}$ and Fig. S10. While the melting chains in the semi-crystalline structure are identified by the melting point $\left(T_{m}\right)$, the amorphous parts are characterized by the glass transition temperature $\left(T_{g}\right)$, which shows from glassy (hard) behavior to the rubbery (soft) behavior of a polymer. If the melting point value is exceeded, all crystal structures of the polymer will melt and only the amorphous structure will remain. Every thermoplastic polymer has a different glass transition temperature as distinctiveness. Thermoplastic polymers have wide melting temperatures in addition to $T_{g}$. Unlike small molecules, polymers do not have a regular molecular weight and cannot melt at a constant temperature.

The thermal behavior of all polymers was measured by DSC and reported in Fig. 2a. The glass transition temperatures $\left(T_{g}\right)$ of the polymers were calculated. While the glass transition temperatures $\left(T_{g}\right)$ were determined between 28 and $35{ }^{\circ} \mathrm{C}$ for PTHF block and, the melting temperatures were obtained between 230 and $250^{\circ} \mathrm{C}$ for Ps block at Fig. 2b. Since the synthesized copolymer contains two different blocks, glass transition and melting temperatures are expected to differ according to the homopolymer structures. 


\section{Initiation}

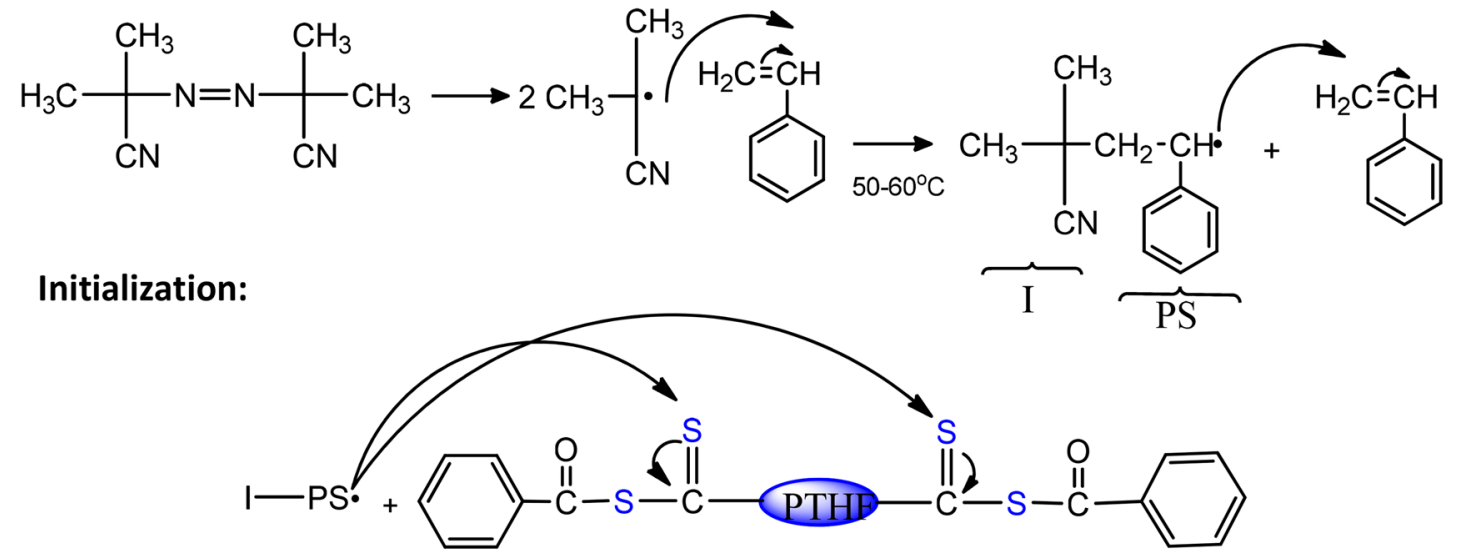

Reinitiation:

$\overbrace{\mathrm{R}}^{\mathrm{R}}$

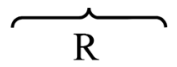

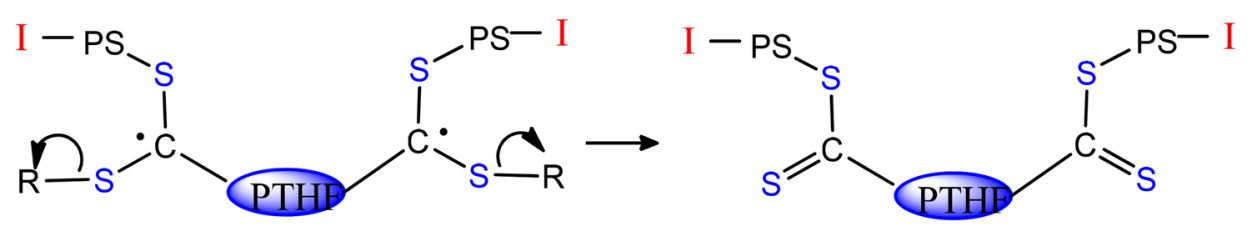

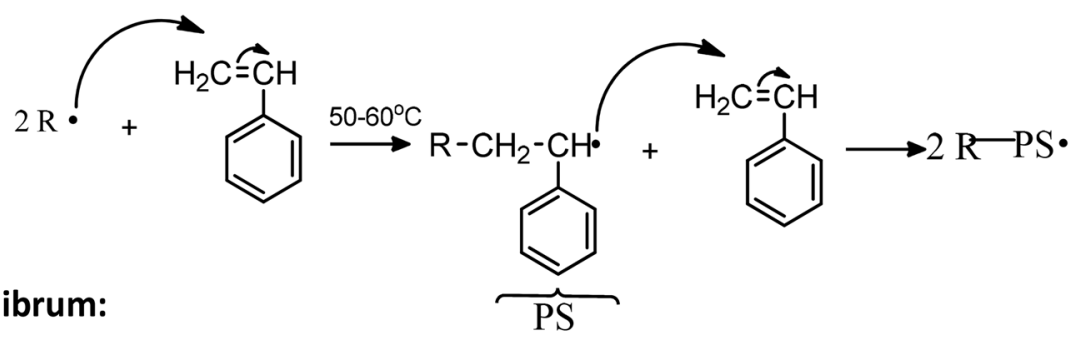

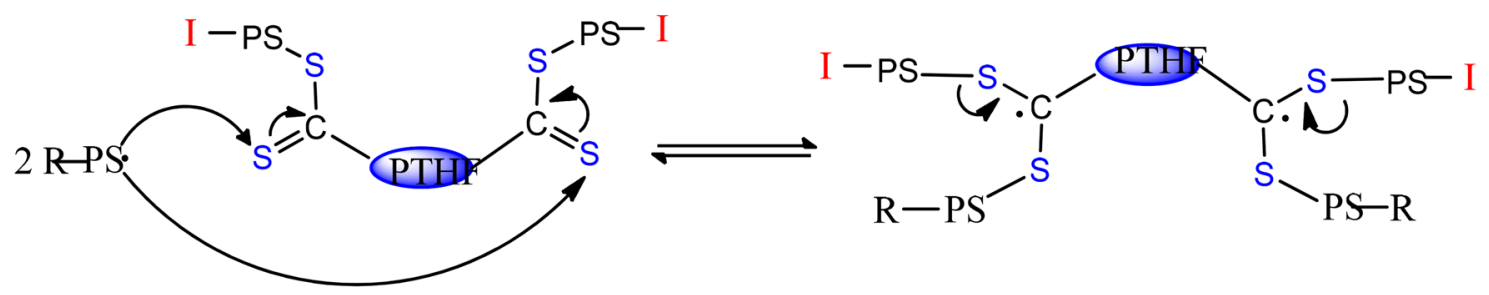

Termination<smiles>[R][R]SC(=S)C1CCCC1C(=S)S[Sb][R]</smiles>

$\mathrm{AB}_{2}$

Scheme 3 Mechanism of the RAFT/MADIX polymerization of styrene 
Table 1 Numerical values of the reaction obtained as a result of styrene polymerization with PTHF-1000 MADIX agent

\begin{tabular}{lllllllll}
\hline Exp. no & Exp. code $^{\mathrm{a}}$ & Time $(\mathrm{h})$ & $\begin{array}{l}\text { Substance } \\
\text { amount }\end{array}$ & $\mathrm{In}[\mathrm{M}]_{\mathrm{o}} /[\mathrm{M}]$ & $\mathrm{M}_{\text {theoric }}(\mathrm{g} / \mathrm{mol})$ & $\mathrm{M}_{\mathrm{GPC}}(\mathrm{g} / \mathrm{mol})^{\mathrm{b}}$ & $\mathrm{PDI}_{\mathrm{W}} / \mathrm{M}_{\mathrm{n}}$ & ${\text { Efficiency }(\%)^{\mathrm{c}}}$ \\
\hline 1 & $\mathrm{PTHP}_{2}$ & 48 & 0.3134 & 0.4228 & 16,532 & 35,591 & 1.44 & 34.48 \\
2 & $\mathrm{PTHP}_{3}$ & 72 & 0.3430 & 0.4748 & 19,400 & 41,752 & 1.42 & 37.74 \\
3 & $\mathrm{PTHP}_{4}$ & 96 & 0.4272 & 0.6348 & 29,171 & 43,500 & 1.43 & 47.01 \\
4 & $\mathrm{PTHP}_{5}$ & 120 & 0.4410 & 0.6639 & 30,936 & 45,142 & 1.42 & 48.51 \\
5 & $\mathrm{PTHP}_{6}$ & 144 & 0.5757 & 1.0033 & 48,798 & 46,230 & 1.41 & 63.33 \\
6 & $\mathrm{PTHP}_{7}$ & 168 & 0.5154 & 0.8370 & 41,673 & 48,507 & 1.38 & 56.71 \\
7 & $\mathrm{PTHP}_{8}$ & 192 & 0.6439 & 1.2322 & 59,000 & 41,968 & 1.42 & 70.84 \\
8 & $\mathrm{PTHP}_{9}$ & 216 & 0.6614 & 1.3005 & 61,298 & 57,199 & 1.26 & 72.76 \\
\hline
\end{tabular}

${ }^{a}$ Each polymerizations were performed in benzene using (PTHF 1000-MADIX agent)

${ }^{b}$ Determined by means of GPC in THF eluent using polystyrene standards

${ }^{c}$ Calculated by gravimetric results

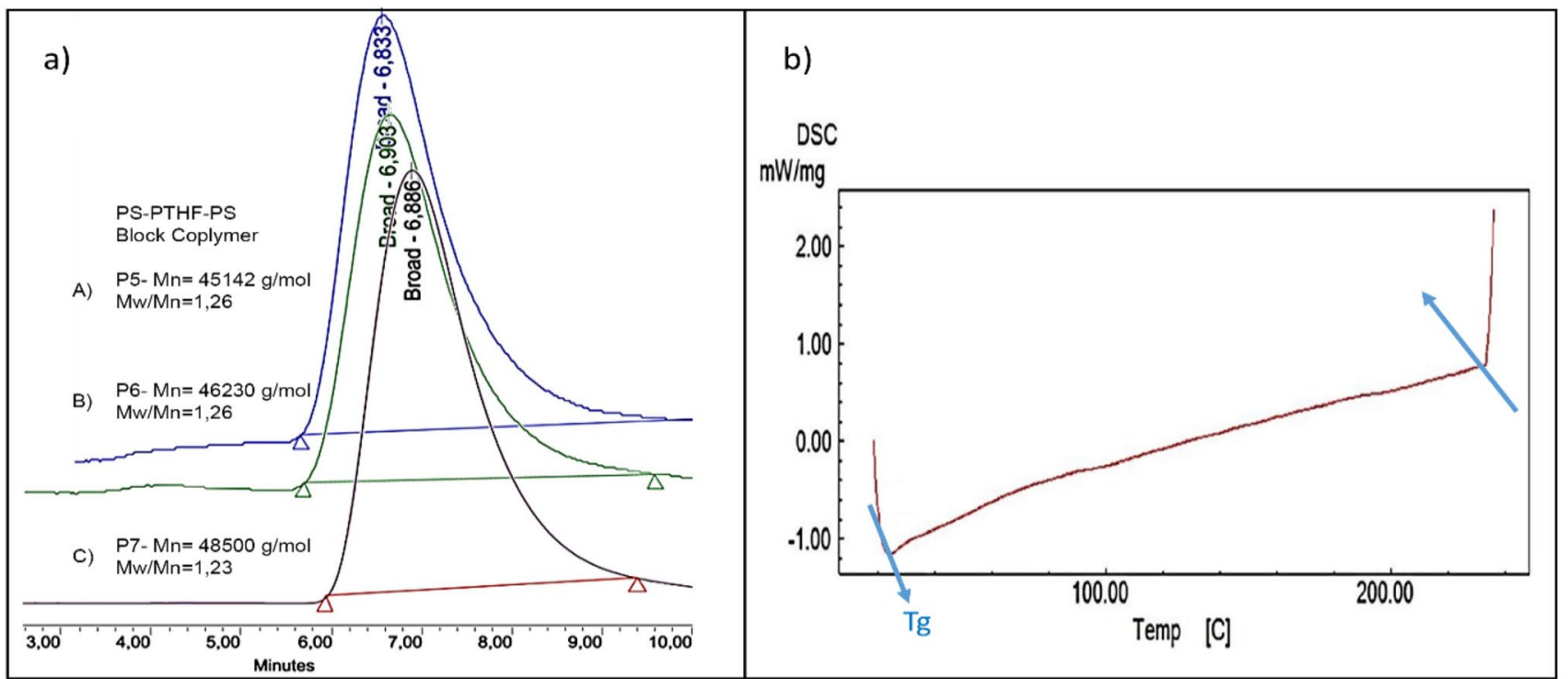

Fig. 2 Overall temperature transitions in GPC traces (a) and DSC analysis (b) of PS-b-PTHF-b-PS

\subsection{Computational details}

\subsubsection{Ground state structural aspects}

The Gaussian 09 W program package was used for the theoretical calculations [44]. All calculations were performed using a DFT study at the B3LYP/6-31G $(d, p)$ basis set [45]. The conformational structure of Avogadro version 1.2 was checked for the preparation of the molecule. However, it was used to visualize and tabulate the input file prepared by the Gausviev program and the data generated after the calculation. The geometry optimization of the synthesized molecule was performed as the first step of the computational study. The lowest energy state of the molecule was determined by the ground state. In particular, it requires the sensitivity of the interaction energy to change the shape of the molecule induced by the movement of the core positions in general. The molecular structure, vibration frequencies and energies of the optimized geometries of poly (tetrahydrofuran) were calculated by using the DFT method.

\subsubsection{Geometry optimization}

The optimized basic state structure of the poly (tetrahydrofuran) (PTHF-MADIX Agent) is given in Fig. 3. The optimized parameters of the title molecules calculated with B3LYP/6-31G (d, p) are listed in Table 2. Optimized 


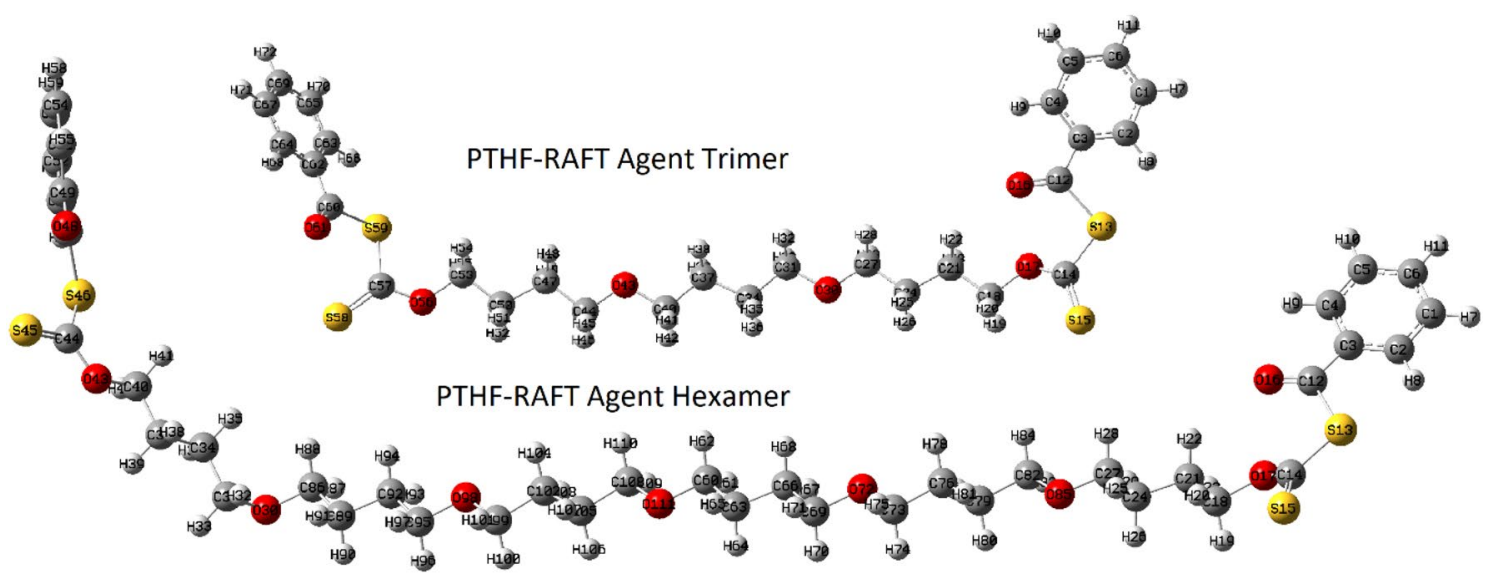

Fig. 3 Optimized structures of poly(tetrahydrofuran) (PTHF-MADIX agent)

Table 2 Theoretically derived bond lengths $(\AA)$ and bond angles $\left(^{\circ}\right)$ of the molecule

\begin{tabular}{|c|c|c|c|c|c|c|c|c|}
\hline \multirow[t]{2}{*}{ Atom groups } & \multicolumn{2}{|c|}{ Bond lengths $(\AA ̊)$} & \multirow[t]{2}{*}{ Atom groups } & \multicolumn{2}{|c|}{ Bond angles $\left({ }^{\circ}\right)$} & \multirow[t]{2}{*}{ Atom groups } & \multicolumn{2}{|c|}{ Dihedral angles $\left({ }^{\circ}\right)$} \\
\hline & Trimer & Hexamer & & Trimer & Hexamer & & Trimer & Hexamer \\
\hline $\mathrm{C} 18 \mathrm{H} 19$ & 1.092 & 1.092 & $\mathrm{H} 8-\mathrm{C} 2-\mathrm{C} 3$ & 120.31 & 120.30 & O17-C14-S13-C12 & -32.90 & -31.47 \\
\hline $\mathrm{C} 18 \mathrm{H} 20$ & 1.093 & 1.093 & H19-C18-O17 & 108.14 & 108.23 & C21-C18-O17-C14 & -155.10 & -157.79 \\
\hline O16C12 & 1.217 & 1.217 & $\mathrm{H} 20-\mathrm{C} 18-\mathrm{H} 19$ & 109.50 & 109.45 & C27-C24-C21-C18 & -179.35 & -179.68 \\
\hline $\mathrm{C} 3-\mathrm{C} 2$ & 1.400 & 1.400 & O16-C12-S13 & 122.82 & 122.83 & C47-C44-O43-C40 & -178.42 & -178.95 \\
\hline O17-C14 & 1.337 & 1.336 & $\mathrm{C} 3-\mathrm{C} 2-\mathrm{C} 1$ & 119.77 & 119.78 & $\mathrm{C} 24-\mathrm{C} 21-\mathrm{C} 18-\mathrm{O} 17$ & -186.65 & -186.08 \\
\hline $\mathrm{C} 12-\mathrm{C} 3$ & 1.479 & 1.479 & O17-C14-S13 & 109.71 & 109.84 & C50-C47-C44-O43 & -179.53 & -179.54 \\
\hline $\mathrm{C} 21-\mathrm{C} 18$ & 1.526 & 1.525 & $\mathrm{C} 21-\mathrm{C} 18-\mathrm{O} 17$ & 104.41 & 104.34 & O43-C40-C37-C34 & -179.19 & -178.97 \\
\hline O43-C40 & 1.458 & 1.456 & C47-C44-O43 & 106.23 & 106.66 & C44-O43-C40-C37 & -180.13 & -179.42 \\
\hline O43-C44 & 1.455 & 1.456 & C24-C21-C18 & 111.34 & 111.39 & C18-O17-C14-S13 & -193.07 & -192.14 \\
\hline O17-C18 & 1.496 & 1.495 & $\mathrm{O} 43-\mathrm{C} 40-\mathrm{C} 37$ & 106.54 & 106.68 & C14-S13-C12-C3 & -189.12 & -189.79 \\
\hline S15-C14 & 1.681 & 1.681 & C44-O43-C40 & 112.91 & 112.78 & $\mathrm{~S} 13-\mathrm{C} 12-\mathrm{C} 3-\mathrm{C} 2$ & -7.55 & -7.25 \\
\hline S13-C14 & 1.846 & 1.845 & C18-O17-C14 & 120.23 & 120.17 & O16-C3-S13-C12 & 2.63 & 2.52 \\
\hline $\mathrm{S} 13-\mathrm{C} 12$ & 1.947 & 1.948 & S15-C14-O17 & 128.70 & 128.64 & S15-S13-O17-C14 & 1.34 & 1.41 \\
\hline
\end{tabular}

structural parameters such as bond length and bond angle of all compounds are determined by the molecule's atomic numbering scheme. The B3LYP method has been used in many studies on metallic-organic compounds and verifies the linearity of the core and the planarity of the environment with optimized structures. Optimized geometries of the PTHF-MADIX Agent were calculated by two methods and minimum potential energy was obtained. Figure 3 shows the optimized structures of the molecule. All bond lengths and bond angles in the phenyl rings are in the normal range. The $\mathrm{C}-\mathrm{C}$ bond distance for the PTHFMADIX agent is the same value as $1.40 \AA$ for the trimer and hexamer. The $\mathrm{C} 18-\mathrm{H} 20$ bond was found to be $1.09 \AA$. All optimized bond lengths are the same in both trimer and hexamer. When examining $\mathrm{S}-\mathrm{C}$ bonds in MADIX agent, according to Table 2, (S15-C14, S13-C14 and S13-C12) bond lengths are $1.68 \AA$, $1.84 \AA$ and $1.95 \AA$, respectively.
The aliphatic bond lengths are uniform throughout the polymer chain. The O43-C40 trimer extends in the range 1.46 and the hexamer $1.45 \AA$.

All $\mathrm{C}-\mathrm{C}-\mathrm{C}$ angles in the aromatic ring are between $111.34^{\circ}$ and $119.06^{\circ}$. In the thio groups, S15-C14-O17 was calculated as $128.70^{\circ}$. Optimized parameters of the selected compounds of trimer and hexamer based on B3LYP/6-31G $(d, p)$ are given in Table 2.

\subsubsection{Frontier molecular orbitals [HOMO-LUMO]}

The highest occupied molecular orbital (HOMO) and the lowest unoccupied molecular orbital (LUMO) are located at the outermost frontiers of the molecule [46-49]. Frontiers molecular orbitals (FMO) are used to determine the electronic and optical properties of the molecule. While HOMO has an electron-donating character, the 
LUMO represents an electron retrieval character. There is a critical dimension for the molecules that the closedshell state gives to the AFM (antiferromagnetic) ground state. The appearance of the AFM state with the size can be attributed to the reduced HOMO-LUMO cavity for the closed-shell state. As the HOMO-LUMO gap approaches zero, it makes the AFM state more stable by electron-electron interaction. Increased HOMO-LUMO clearance indicates increased stability. This increased stability can be explained by Clar's rule of six; that is, stability increases with the number of aromatic. The two rings on the edges of the molecules increase the number of hexes up to two, thus making the respective molecules more stable. The critical dimension shows the view of the AFM ground state and hence the difficulty in carrying out a synthesis. This suggests that determining the critical dimension can indeed explain the synthesis difficulty
Table 3 Electronegativity $(\chi)$ and global electrophile $(\omega)$ etc. values

\begin{tabular}{lrr}
\hline Molecular parameters & Trimer & Hexamer \\
\hline$E_{\mathrm{HOMO}}(\mathrm{eV})$ & -5.8943 & -5.9028 \\
$E_{\mathrm{LUMO}}(\mathrm{eV})$ & -2.1728 & -2.1541 \\
Energy gap $(\Delta)\left|\mathrm{E}_{\mathrm{HOMO}}-\mathrm{E}_{\mathrm{LUMO}}\right|$ & 3.7215 & 3.7487 \\
lonization potential $\left(I=-\mathrm{E}_{\mathrm{HOMO}}\right)$ & 2.1728 & 2.1541 \\
Electron affinity $\left(A=-E_{\mathrm{LUMO}}\right)$ & 5.8943 & 5.9028 \\
Electronegativity $(\chi=(I+A) / 2)$ & 4.0335 & 4.0284 \\
Chemical potential $(\mu=-(I+A) / 2)$ & -4.0335 & -4.0284 \\
Chemical hardness $(\eta=(I-A) / 2)$ & 1.8607 & 1.8743 \\
Chemical softness $(S=1 / 2 \eta)$ & 0.9303 & 0.9371 \\
Electrophilicity index $\left(\omega=\mu^{2} / 2 \eta\right)$ & 4.3717 & 4.3290 \\
\hline
\end{tabular}

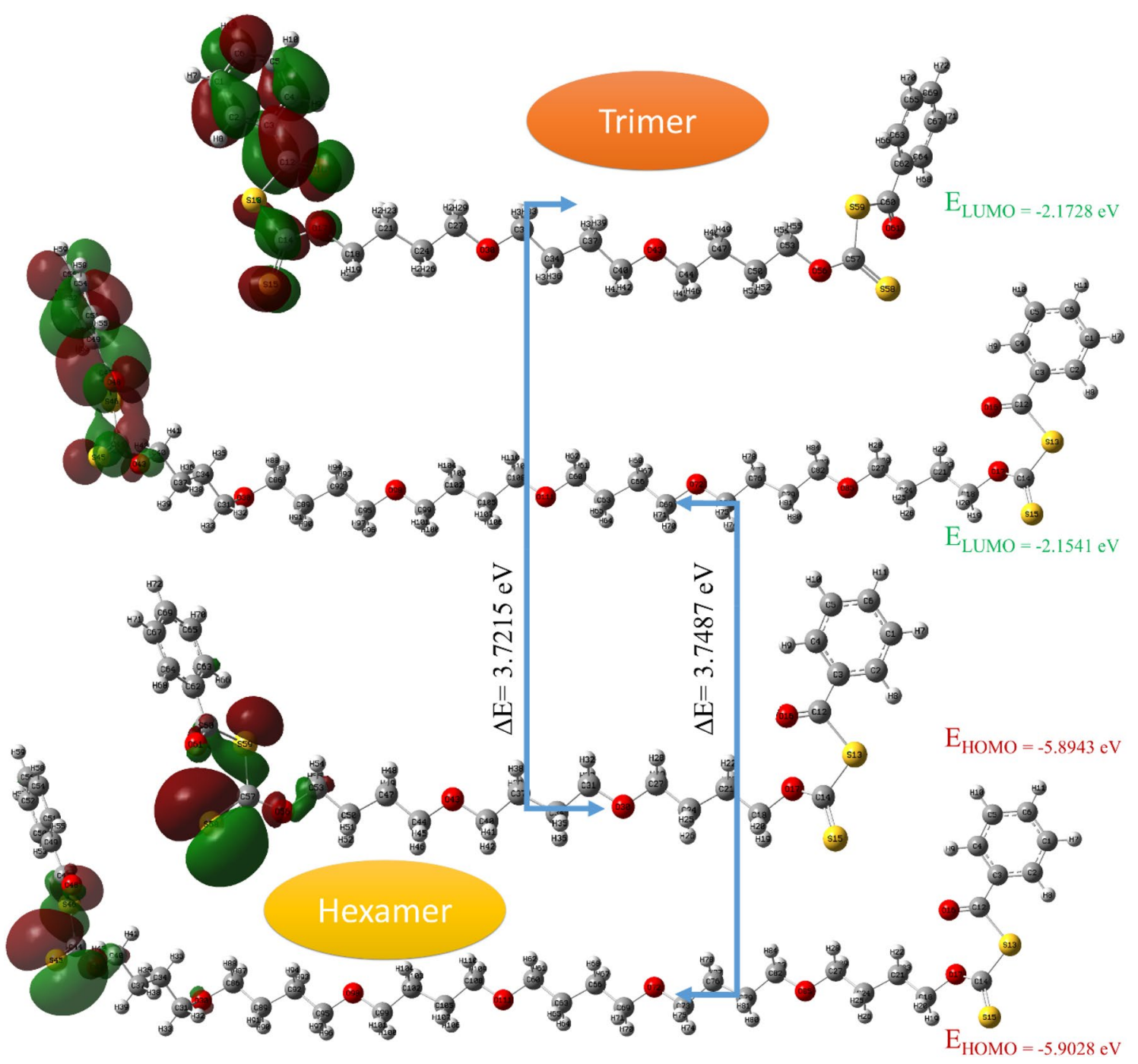

Fig. 4 Visual and energy values of HOMO, and LUMO for trimer and hexamer shape of PTHF-MADIX Agent 
and therefore guide experimental efforts [50]. Figure 4 shows the visual and energy values of $\mathrm{HOMO}, \mathrm{HOMO}_{-1}$, LUMO and $\mathrm{LUMO}_{+1}$ for the PTHF-MADIX Agent [51-53]. It is seen that LUMOs are mostly concentrated on sulfur atoms. The HOMOs of all molecules have shifted towards heterocyclic rings and some benzene rings.

The PTHF-MADIX agent is stable and provides an efficient electron transfer. From Table 3, HOMO $-5.8943 \mathrm{eV}$-LUMO $-2.1728 \mathrm{eV}$ value for trimer and HOMO - 5.9028 eV-LUMO - 2.1541 eV value for hexamer were calculated. The energy difference between LUMO/ $\mathrm{HOMO}$ was calculated for the trimer and the hexamer and found to be $\Delta \mathrm{E}=3.7215 \mathrm{eV}$ and $3.7487 \mathrm{eV}$ respectively. In the present study, the chemical potential $(\mu)$ of the PTHFMADIX Agent was found to be 4.0335 and $4.0284 \mathrm{eV}$ for the trimer and the hexamer, respectively. The higher the electronic chemical potential (absolute values), the less stable or more reactive the compound. Various molecular parameters are presented in Table 3; such as the electronic chemical potential $(\mu)$, the electronegativity $(\chi)$, the global electrophilic $(\omega)$ the ionization potential (I) and the electron affinity $(\mathrm{A})$ is calculated from LUMO and HOMO orbital energies.

\subsubsection{Molecular electrostatic potential surface}

The determination of molecular activity and monitoring of the structure on a single scale with the electrostatic potential map of the molecule is a very useful feature [54]. With this map, it is possible to determine the electrophilic attack and the direction of nucleophilic reactions, the hydrogen bond affinity and many molecular sensitivities. Different color codes are used when performing the MEP analysis of the molecule [55]. Here, red, blue and green colors are used and delocalization of the colors according to the electronic density.
Here, the red electron-rich, blue electron deficiency and the green offers neutral potential. In this study, the molecular electrostatic potential (MEP) [40] maps were mapped to the PTHF-MADIX agent as shown in Fig. 5 . In the case of the PTHF-MADIX agent, trimer and hexamer were examined. The electrostatic map, with red color around oxygen atoms, is observed on both oxygen and thio carbonyl thio polymer atoms. The absence of a clear blue indicates the lack of a positive region. The hydrogen atoms (blue-green) in the structure represent the positive charge. The green color in both aromatic and aliphatic chain groups shows an almost neutral potential.

\subsubsection{Natural bond orbital (NBO) analysis}

The natural bond orbital analysis is explored in the study of the interaction between intramolecular and intermolecular interactions with charge transfer and conjugate interactions in both full and virtual orbital spaces [55-58]. NBO analysis was performed at DFT/B3LYP/6-31 $G(d, p)$ with Gaussian version. All orbitals belonging to the presence of intramolecular delocalization or hyperconjugation were obtained by analysis. The analyzed results are given in Table 4. In addition, the intramolecular charge transfer of the $\pi$-electron increases the polarity of the molecule and may be responsible for its NBO properties.

Intramolecular interactions are observed as an increase in electron density (ED) in the ( $\mathrm{S}-\mathrm{O}$ ) bonding orbitals bonds. The electron density of the conjugated substituted bond (1.996 au) clearly shows a strong delocalization. The occupancy rate of the $\pi$ bonds is lower than the $\sigma$ bonds and this provides more localization. Delocalization of $\sigma(\mathrm{C} 2-\mathrm{C} 3)$ electrons in the ring and hyperconjugative effect increases the stabilization of the molecule. C1-C6 $\pi^{*}, \mathrm{C} 4-\mathrm{C} 5 \pi^{*}, \mathrm{C} 12-\mathrm{O} 16 \pi^{*}, \pi$ bond indicates a strong conjugation of $17.64-23.44 \mathrm{kcal} / \mathrm{mol}$.
Fig. 5 Molecular electrostatic (MEP) maps of trimer and hexamer structures of PTHFMADIX agent compound

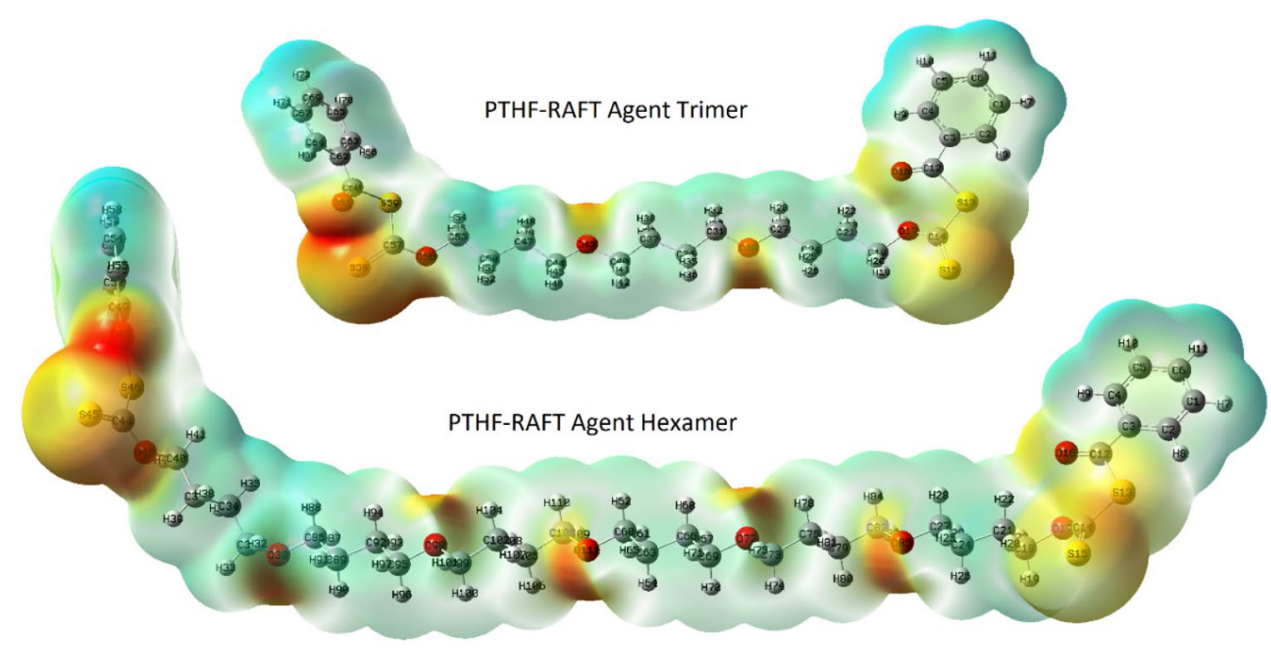


Table 4 Selected NBO results show the formation of Lewis and non-Lewis orbitals using the B3LYP/6-31 G (d, p) level of theory

\begin{tabular}{|c|c|c|c|c|c|c|c|c|}
\hline NBO(i) & Type & ED/e & $\mathrm{NBO}(\mathrm{j})$ & Type & $\mathrm{ED} / / \mathrm{e}$ & $\mathrm{E}^{\mathrm{a}}(\mathrm{Kcal} / \mathrm{mol})$ & $E(j)-E(i)^{b}$ (a.u.) & $F(i, j)^{C}(a . u)$ \\
\hline \multirow[t]{10}{*}{$\mathrm{C} 2-\mathrm{C} 3$} & \multirow[t]{7}{*}{$\sigma$} & \multirow[t]{7}{*}{$1.97,507$} & $\mathrm{C} 1-\mathrm{C} 2$ & $\sigma^{*}$ & 0.01644 & 2.93 & 1.29 & 0.055 \\
\hline & & & $\mathrm{C} 1-\mathrm{H} 7$ & $\sigma^{*}$ & 0.01095 & 1.80 & 1.19 & 0.041 \\
\hline & & & $\mathrm{C} 2-\mathrm{H} 8$ & $\sigma^{*}$ & 0.01396 & 1.34 & 1.19 & 0.036 \\
\hline & & & $\mathrm{C} 3-\mathrm{C} 4$ & $\sigma^{*}$ & 0.02435 & 4.53 & 1.27 & 0.068 \\
\hline & & & $\mathrm{C} 3-\mathrm{C} 12$ & $\sigma^{*}$ & 0.06128 & 2.28 & 1.14 & 0.046 \\
\hline & & & $\mathrm{C} 4-\mathrm{H} 9$ & $\sigma^{*}$ & 0.01498 & 1.54 & 1.20 & 0.038 \\
\hline & & & C12-016 & $\sigma^{*}$ & 0.01082 & 1.53 & 1.23 & 0.039 \\
\hline & \multirow[t]{3}{*}{$\pi$} & \multirow[t]{3}{*}{1.63564} & $\mathrm{C} 1-\mathrm{C} 6$ & $\pi^{*}$ & 0.01653 & 17.64 & 0.28 & 0.063 \\
\hline & & & $\mathrm{C} 4-\mathrm{C} 5$ & $\pi^{*}$ & 0.28845 & 20.09 & 0.28 & 0.068 \\
\hline & & & $\mathrm{C} 12-\mathrm{O} 16$ & $\pi^{*}$ & 0.20508 & 23.44 & 0.24 & 0.070 \\
\hline \multirow[t]{5}{*}{$\mathrm{C} 2-\mathrm{H} 8$} & \multirow[t]{5}{*}{$\sigma$} & \multirow[t]{5}{*}{1.97809} & $\mathrm{C} 1-\mathrm{C} 2$ & $\sigma^{*}$ & 0.01644 & 1.35 & 1.11 & 0.035 \\
\hline & & & $\mathrm{C} 1-\mathrm{C} 6$ & $\sigma^{*}$ & 0.01653 & 2.90 & 1.10 & 0.050 \\
\hline & & & $\mathrm{C} 2-\mathrm{C} 3$ & $\sigma^{*}$ & 0.02521 & 1.48 & 1.09 & 0.036 \\
\hline & & & C3-C4 & $\sigma^{*}$ & 0.02435 & 3.42 & 1.08 & 0.054 \\
\hline & & & S13-C14 & $\sigma^{*}$ & 0.09327 & 0.96 & 0.64 & 0.022 \\
\hline C4-C5 & $\sigma$ & 1.97916 & $\mathrm{C} 3-\mathrm{C} 12$ & $\sigma^{*}$ & 0.06128 & 2.58 & 1.14 & 0.049 \\
\hline \multirow[t]{7}{*}{$\mathrm{C} 12-\mathrm{S} 13$} & \multirow[t]{7}{*}{$\sigma$} & \multirow[t]{7}{*}{1.97404} & $\mathrm{C} 3-\mathrm{C} 4$ & $\sigma^{*}$ & 0.02435 & 2.62 & 1.11 & 0.048 \\
\hline & & & $\mathrm{C} 3-\mathrm{C} 12$ & $\sigma^{*}$ & 0.06128 & 0.63 & 0.98 & 0.022 \\
\hline & & & $\mathrm{C} 12-\mathrm{S} 13$ & $\sigma^{*}$ & 0.20193 & 0.81 & 0.61 & 0.021 \\
\hline & & & S13-C14 & $\sigma^{*}$ & 0.09327 & 0.82 & 0.66 & 0.021 \\
\hline & & & C14-S15 & $\sigma^{*}$ & 0.10070 & 0.79 & 0.75 & 0.022 \\
\hline & & & C14-S15 & $\pi^{*}$ & 0.08567 & 1.70 & 0.51 & 0.029 \\
\hline & & & $\mathrm{C} 14-\mathrm{O} 17$ & $\sigma^{*}$ & 0.02435 & 0.89 & 0.85 & 0.025 \\
\hline \multirow[t]{2}{*}{ C12-O16 } & \multirow[t]{2}{*}{$\sigma$} & \multirow[t]{2}{*}{1.99719} & $\mathrm{C} 2-\mathrm{C} 3$ & $\sigma^{*}$ & 0.02521 & 0.86 & 1.70 & 0.034 \\
\hline & & & C3-C12 & $\sigma^{*}$ & 0.06128 & 0.72 & 1.57 & 0.031 \\
\hline C12-016 & $\pi$ & 1.98172 & $\mathrm{C} 2-\mathrm{C} 3$ & $\pi^{*}$ & 0.02521 & 4.90 & 0.41 & 0.044 \\
\hline \multirow[t]{2}{*}{ S13-C14 } & \multirow[t]{2}{*}{$\sigma$} & \multirow[t]{2}{*}{1.97931} & C3-C12 & $\sigma^{*}$ & 0.06128 & 0.57 & 1.05 & 0.022 \\
\hline & & & O17-C18 & $\sigma^{*}$ & 0.03829 & 3.40 & 0.80 & 0.047 \\
\hline \multirow[t]{5}{*}{ C14-S15 } & \multirow[t]{2}{*}{$\sigma$} & \multirow[t]{2}{*}{1.98084} & C14-S15 & $\sigma^{*}$ & 0.10070 & 0.95 & 0.85 & 0.026 \\
\hline & & & C14-S15 & $\pi^{*}$ & 0.35867 & 3.36 & 0.62 & 0.045 \\
\hline & $\pi$ & 1.97425 & $\mathrm{C} 12-\mathrm{S} 13$ & $\sigma^{*}$ & 0.20193 & 1.12 & 0.41 & 0.020 \\
\hline & & & C14-S15 & $\sigma^{*}$ & 0.10070 & 2.92 & 0.55 & 0.036 \\
\hline & & & C14-S15 & $\pi^{*}$ & 0.35867 & 8.07 & 0.31 & 0.049 \\
\hline O17-C18 & $\sigma$ & 1.97978 & S13-C14 & $\sigma^{*}$ & 0.09327 & 3.11 & 0.87 & 0.047 \\
\hline & & & C21-C24 & $\sigma^{*}$ & 0.01284 & 1.79 & 1.14 & 0.040 \\
\hline C18-H19 & $\sigma$ & 1.98814 & O17-C18 & $\sigma^{*}$ & 0.03829 & 0.88 & 0.70 & 0.022 \\
\hline & & & $\mathrm{C} 21-\mathrm{H} 22$ & $\sigma^{*}$ & 0.01400 & 1.88 & 0.99 & 0.038 \\
\hline $\mathrm{C} 18-\mathrm{H} 20$ & $\sigma$ & 1.98838 & O17-C18 & $\sigma^{*}$ & 0.03829 & 1.24 & 0.70 & 0.027 \\
\hline & & & C18-C21 & $\sigma^{*}$ & 0.01425 & 0.51 & 0.90 & 0.019 \\
\hline & & & $\mathrm{C} 21-\mathrm{H} 23$ & $\sigma^{*}$ & 0.01239 & 2.10 & 0.97 & 0.040 \\
\hline C40-H41 & $\sigma$ & 1.98755 & C37-H39 & $\sigma^{*}$ & 0.01260 & 2.09 & 0.98 & 0.040 \\
\hline & & & C37-C40 & $\sigma^{*}$ & 0.01484 & 0.52 & 0.90 & 0.019 \\
\hline & & & $\mathrm{C} 40-\mathrm{O} 43$ & $\sigma^{*}$ & 0.03982 & 1.11 & 0.71 & 0.025 \\
\hline $\mathrm{C} 40-\mathrm{H} 42$ & $\sigma$ & 1.98732 & $\mathrm{C} 37-\mathrm{H} 38$ & $\sigma^{*}$ & 0.01251 & 2.09 & 0.98 & 0.040 \\
\hline & & & $\mathrm{C} 40-043$ & $\sigma^{*}$ & 0.03982 & 1.03 & 0.71 & 0.024 \\
\hline C40-043 & $\sigma$ & 1.98481 & C34-C37 & $\sigma^{*}$ & 0.01476 & 1.70 & 1.14 & 0.039 \\
\hline & & & C44-S45 & $\sigma^{*}$ & 0.31954 & 0.65 & 0.75 & 0.021 \\
\hline & & & C44-S45 & $\pi^{*}$ & 0.09590 & 2.74 & 0.98 & 0.047 \\
\hline
\end{tabular}

${ }^{a} E(2)$ means energy of hyper conjugative interaction (stabilization energy)

${ }^{b}$ Energy difference between donor and acceptor $i$ and $j$ NBO orbitals

${ }^{\mathrm{C}} \mathrm{F}(\mathrm{i}, \mathrm{j})$ is the Fock matrix element between $\mathrm{i}$ and $\mathrm{j}$ NBO orbitals 


\section{Conclusion}

In conclusion, the usability of the xanthate group MADIX agent, which contain polytetrahydrofuran (PTHF) $\left(\mathrm{M}_{\mathrm{W}}\right.$ : $1000 \mathrm{~g} / \mathrm{mol}$ ) polymer block, was investigated in styrenecontrolled polymerization and, the spectroscopic characterization of the MADIX agent was performed. The better control range was obtained by changing the MADIX agent/ monomer/initiator ratio. The theoretical study of the trimer and hexamer of the synthesized polymeric macro MADIX agent was optimized using the DFT/B3LYP method with the 6-31G $(d, p)$ basis set. We have calculated the frontier orbitals, MEP and thermodynamic properties. If the frontier orbital energy gap of molecules is lower (were found for trimer and hexamer and $\Delta \mathrm{E}=3.7215 \mathrm{eV}$ and $3.7487 \mathrm{eV}$ ), makes the dipole moment and polarity values of the molecule more reactive and more polar. The existing quantum chemical study can also play an important role in understanding the copolymer dynamics.

\section{Compliance with ethical standards}

Conflict of interest The authors declare that they have no conflict of interest.

\section{References}

1. Siljanovska Petreska G, Auschra C, Paulis M (2018) Confinement driven crystallization of $A B A$ crystalline-soft-crystalline block copolymers synthesized via RAFT mediated miniemulsion polymerization. Polymer 158:327-337. https://doi.org/10.1016/j. polymer.2018.10.073

2. Song $C$ et al (2016) Preparation of thermo-responsive graft copolymer by using a novel macro-RAFT agent and its application for drug delivery. Mater Sci Eng C 62:45-52. https://doi. org/10.1016/j.msec.2016.01.026

3. Levit M et al (2018) Synthesis and characterization of welldefined poly(2-deoxy-2-methacrylamido-D-glucose) and its biopotential block copolymers via RAFT and ROP polymerization. Eur Polym J 105:26-37. https://doi.org/10.1016/j.eurpo lymj.2018.05.018

4. Gopinath A, Sultan Nasar A (2018) Fluorescent star ATRP initiators and fluorescent star poly(methyl methacrylate)s: synthesis and photophysical properties. Polymer 153:139-149. https:// doi.org/10.1016/j.polymer.2018.08.010

5. Guo R, Jacob KI (2014) Effect of chain length distribution on thermal characteristics of model polytetrahydrofuran (PTHF) networks. Polymer 55(17):4468-4477. https://doi.org/10.1016/j. polymer.2014.06.026

6. Mahmoudian M, Kochameshki MG, Hosseinzadeh M (2018) Modification of graphene oxide by ATRP: a pH-responsive additive in membrane for separation of salts, dyes and heavy metals. J Environ Chem Eng 6(2):3122-3134. https://doi.org/10.1016/j. jece.2018.04.056

7. Alsubaie $\mathrm{F}$ et al (2019) Thermoresponsive viscosity of polyacrylamide block copolymers synthesised via aqueous Cu-RDRP.
Eur Polym J 114:326-331. https://doi.org/10.1016/j.eurpo Iymj.2019.02.045

8. Benvenuta-Tapia JJ et al (2019) Enhanced asphalt performance upon addition of RAFT-synthesized reactive multi-block copolymers. Mater Chem Phys 227:269-278. https://doi.org/10.1016/j. matchemphys.2019.02.004

9. Goel V et al (2018) Structure of block copolymer grafted silica nanoparticles. Polymer 159:138-145. https://doi.org/10.1016/j. polymer.2018.10.072

10. Radke W (2019) The retention behavior of diblock copolymers in gradient chromatography; Similarities of diblock copolymers and homopolymers. J Chromatogr A 1593:17-23. https://doi. org/10.1016/j.chroma.2019.01.043

11. Yang Y-L, Sheng Y-J, Tsao H-K (2019) Hybridization of lipids to monolayer and bilayer membranes of triblock copolymers. J Colloid Interface Sci 544:53-60. https://doi.org/10.1016/j. jcis.2019.02.071

12. Lee EJ et al (2018) Effect of azo and peroxide initiators on a kinetic study of methyl methacrylate free radical polymerization by DSC. Macromol Res 26(4):322-331. https://doi.org/10.1007/ s13233-018-6047-6

13. Bağlan $M$ et al (2018) Synthesis of PMMA-b-PEG-b- PMMA by controlled polymerization using Macro-RAFT agents. J Inst Sci Technol 8(3):243-254. https://doi.org/10.21597/jist.428201

14. Matyjaszewski K, Spanswick J (2005) Controlled/living radical polymerization. Mater Today 8(3):26-33. https://doi. org/10.1016/S1369-7021(05)00745-5

15. Barsbay M, Güven O (2018) Nanostructuring of polymers by controlling of ionizing radiation-induced free radical polymerization, copolymerization, grafting and crosslinking by RAFT mechanism. Radiat Phys Chem. https://doi.org/10.1016/j.radph yschem.2018.04.009

16. Fliedel C, Poli R (2019) Homolytically weak metal-carbon bonds make robust controlled radical polymerizations systems for "less-activated monomers". J Organomet Chem 880:241-252. https://doi.org/10.1016/j.jorganchem.2018.11.012

17. Jia $T$ et al (2019) Examining derivatives of quinacridone, diketopyrrolopyrrole and indigo as the visible-light organic photocatalysts for metal-free atom transfer radical polymerization. Dyes Pigm 165:223-230. https://doi.org/10.1016/j.dyepi g.2019.01.060

18. Jung J, Park C, Yun GJ (2019) Free radical polymerization simulation and molecular entanglement effect on large deformation behavior. Eur Polym J 114:223-233. https://doi.org/10.1016/j. eurpolymj.2019.02.042

19. Sosnowski S, Szymanski R (2019) A novel efficient hybrid algorithm for Monte Carlo simulation of controlled radical polymerization: the method integrating reactive and deactivated species. Chem Eng J 358:197-210. https://doi.org/10.1016/j. cej.2018.09.154

20. Jing $Y$ et al (2016) Synthesis of a bulky nitroxide and its application in the nitroxide-mediated radical polymerization. Tetrahedron 72(48):7665-7671. https://doi.org/10.1016/j. tet.2016.04.008

21. Kermagoret A, Gigmes D (2016) Combined nitroxide mediated radical polymerization techniques for block copolymer synthesis. Tetrahedron 72(48):7672-7685. https://doi.org/10.1016/j. tet.2016.07.002

22. Qiao XG et al (2019) Nitroxide-mediated polymerization of methacrylates in the presence of 4-vinyl pyridine as controlling comonomer. Polymer 172:330-338. https://doi.org/10.1016/j. polymer.2019.04.003

23. Liu X-H et al (2016) Dithiobenzoic copper(II): a novel, facile, and stable mediating agent combining ATRP and RAFT features for reversible deactivation radical polymerization of 
methacrylates. Polymer 107:170-176. https://doi.org/10.1016/j. polymer.2016.11.019

24. Gruszkiewicz A et al (2018) Enhancement of the growth of polymer brushes via ATRP initiated from ions-releasing indium tin oxide substrates. Eur Polym J. https://doi.org/10.1016/j.eurpo lymj.2018.11.004

25. Latelli $\mathrm{N}$ et al (2014) Mechanism of addition-fragmentation reaction of thiocarbonyls compounds in free radical polymerization. A DFT study. Comput Theor Chem 1027:39-45. https:// doi.org/10.1016/j.comptc.2013.10.018

26. Li Y et al (2009) Selective recognition and removal of chlorophenols from aqueous solution using molecularly imprinted polymer prepared by reversible addition-fragmentation chain transfer polymerization. Biosens Bioelectron 25(2):306-312. https://doi.org/10.1016/j.bios.2009.07.001

27. Hannachi $D$ et al (2015) Addition-fragmentation reaction of thionoesters compounds in free-radical polymerisation (methyl, cyanomethyl and styryl): a theoretical interpretation. Mol Phys 113(13-14):1541-1550. https://doi.org/10.1080/00268 976.2014 .985275

28. Segura T et al (2016) Synthesis of narrow molecular weight distribution polyvinyl acetate by gamma-rays initiated RAFT/ MADIX miniemulsion polymerization. Polymer 102:183-191. https://doi.org/10.1016/j.polymer.2016.09.004

29. Simonova YA et al (2020) Impact of the RAFT/MADIX agent on protonated diallylammonium monomer cyclopolymerization with efficient chain transfer to monomer. Eur Polym J 122:109363. https://doi.org/10.1016/j.eurpolymj.2019.109363

30. Uyar Z et al (2019) Synthesis and characterization of well-defined end-chain functional macrophotoinitiators of polystyrene and polyacrylonitrile by RAFT/MADIX polymerization. Eur Polym J 119:102-113. https://doi.org/10.1016/j.eurpolymj.2019.07.028

31. lijima K et al (2017) Synthesis of rotaxane cross-linked polymers with supramolecular cross-linkers based on $\gamma-C D$ and PTHF macromonomers: the effect of the macromonomer structure on the polymer properties. Polymer 128:392-396. https://doi. org/10.1016/j.polymer.2017.01.024

32. Czech $Z$ et al (2008) Novel azo-peresters radical initiators used for the synthesis of acrylic pressure-sensitive adhesives. Express Polym Lett 2:277-283. https://doi.org/10.3144/expresspolymlet t.2008.33

33. De Proft F, Geerlings $P$ (2001) Conceptual and computational DFT in the study of aromaticity. Chem Rev 101(5):1451-1464. https://doi.org/10.1021/cr9903205

34. Kulinich AV, Ishchenko AA (2019) Electronic structure of merocyanine dyes derived from $3 \mathrm{H}$-indole and malononitrile in the ground and excited states: DFT/TD-DFT analysis. Comput Theor Chem 1154:50-56. https://doi.org/10.1016/j.compt c. 2019.03.018

35. Samiee $S$, Hossienpour $P$ (2019) Tuning the electronic and optical properties of $\mathrm{Pt}$ (diimine)(dithiolate) complexes through different anchoring groups; a DFT/TD-DFT study. Inorg Chim Acta 494:13-20. https://doi.org/10.1016/j.ica.2019.05.006

36. Cabir B et al (2020) Computational DFT calculations, photovoltaic properties and synthesis of (2R, 3S)-2, 3, 4-trihydroxybutoxy substituted phthalocyanines. Inorg Nano-Metal Chem. https:// doi.org/10.1080/24701556.2020.1725051

37. Bhuvaneswari $R$ et al (2018) Molecular structure, vibrational spectroscopic (FT-IR, FT-Raman), NBO, HOMO and LUMO analysis of morpholinium oxalate by density functional method. J Mol Struct 1173:188-195. https://doi.org/10.1016/j.molst ruc.2018.06.109

38. Binoy J, Marchewka MK, Jayakumar VS (2013) The 'partial resonance' of the ring in the NLO crystal melaminium formate: study using vibrational spectra, DFT, HOMO-LUMO and MESP mapping. Spectrochim Acta Part A Mol Biomol Spectrosc 104:97-109. https://doi.org/10.1016/j.saa.2012.11.046

39. Prabhaharan M et al (2015) DFT studies on vibrational spectra, HOMO-LUMO, NBO and thermodynamic function analysis of cyanuric fluoride. Spectrochim Acta Part A Mol Biomol Spectrosc 136:494-503. https://doi.org/10.1016/j.saa.2014.09.062

40. Priya MK et al (2019) Molecular structure, spectroscopic (FT-IR, FT-Raman, 13C and 1H NMR) analysis, HOMO-LUMO energies, Mulliken, MEP and thermal properties of new chalcone derivative by DFT calculation. Mater Today Proc 8:37-46. https://doi. org/10.1016/j.matpr.2019.02.078

41. Solğun DG et al (2020) DFT analysis and electronic properties, and synthesis of tetra (9-phenyl-9H-xanthen-9-yl) oxy peripheral-substituted zinc phthalocyanine. Chem Pap. https://doi. org/10.1007/s11696-020-01087-4

42. Kartal B et al (2014) Study of solution polymerization of styrene in the presence of poly(ethylene glycol)-RAFT agents possessing benzoyl xanthate derivatives. J Macromol Sci Part A 51(12):990-998. https://doi.org/10.1080/10601 325.2014 .967096

43. Fukuda T et al (1996) Well-defined block copolymers comprising styrene-acrylonitrile random copolymer sequences synthesized by "living" radical polymerization. Macromolecules 29(8):30503052. https://doi.org/10.1021/ma951792y

44. Frisch MJ, Schlegel HB, Scuseria GE, Robb MA, Cheeseman JR, Scalmani G, Barone V, Mennucci B, Petersson GA et al. (2009) Gaussian 09. Revision D.01. Gaussian, Inc., Wallingford. https:// gaussian.com/gaussian16/

45. Becke AD (1988) Density-functional exchange-energy approximation with correct asymptotic behavior. Phys Rev A 38(6):3098-3100. https://doi.org/10.1103/PhysRevA.38.3098

46. Gayathri R, Arivazhagan M (2011) Vibrational spectroscopy investigation and HOMO, LUMO analysis using DFT (B3LYP) on the structure of 1,3-dichloro 5-nitrobenzene. Spectrochim Acta Part A Mol Biomol Spectrosc 81(1):242-250. https://doi. org/10.1016/j.saa.2011.06.005

47. Latha B et al (2018) HOMO-LUMO analysis of multi walled carbon nanotubes doped Tetrafluoro Phthalate crystals for nonlinear optical applications. J Mol Struct 1152:351-360. https://doi. org/10.1016/j.molstruc.2017.09.097

48. Mıhçıokur Ö, Özpozan T (2017) Molecular structure, vibrational spectroscopic analysis (IR \& Raman), HOMO-LUMO and NBO analysis of anti-cancer drug sunitinib using DFT method. J Mol Struct 1149:27-41. https://doi.org/10.1016/j.molst ruc.2017.07.064

49. Shafieyoon P, Mehdipour E, Mary YS (2019) Synthesis, characterization and biological investigation of glycine-based sulfonamide derivative and its complex: vibration assignment, HOMO-LUMO analysis, MEP and molecular docking. J Mol Struct 1181:244-252. https://doi.org/10.1016/j.molstruc.2018.12.067

50. Jiang D-E, Dai S (2008) Circumacenes versus periacenes: HOMOLUMO gap and transition from nonmagnetic to magnetic ground state with size. Chem Phys Lett 466(1):72-75. https:// doi.org/10.1016/j.cplett.2008.10.022

51. Balachandran V et al (2015) Spectroscopic investigation, natural bond orbital analysis, HOMO-LUMO and thermodynamic functions of 2-tert-butyl-5-methyl anisole using DFT (B3LYP) calculations. Spectrochim Acta Part A Mol Biomol Spectrosc 136:451-463. https://doi.org/10.1016/j.saa.2014.09.057

52. El-Mansy MAM et al (2013) DFT approach for FT-IR spectra and HOMO-LUMO energy gap for $\mathrm{N}$-( $\mathrm{p}$-dimethylaminobenzylidene)p-nitroaniline (DBN). Spectrochim Acta Part A Mol Biomol Spectrosc 111:217-222. https://doi.org/10.1016/j.saa.2013.04.018

53. Nageswari G et al (2018) Electronic and vibrational spectroscopic (FT-IR and FT-Raman) investigation using ab initio (HF) and DFT (B3LYP and B3PW91) and HOMO/LUMO/MEP analysis 
on the structure of L-serine methyl ester hydrogen chloride. J Mol Struct 1166:422-441. https://doi.org/10.1016/j.molst ruc.2018.04.014

54. Demircioğlu Z et al (2019) Spectroscopic, XRD, Hirshfeld surface and DFT approach (chemical activity, ECT, NBO, FFA, NLO, MEP, NPA\& MPA) of (E)-4-bromo-2-[(4-bromophenylimino) methyl]-6-ethoxyphenol. J Mol Struct 1191:129-137. https:// doi.org/10.1016/j.molstruc.2019.03.060

55. Hakiri R et al (2018) Synthesis, X-ray structural, Hirshfeld surface analysis, FTIR, MEP and NBO analysis using DFT study of a 4-chlorobenzylammonium nitrate $\left(\mathrm{C}_{7} \mathrm{ClH}_{9} \mathrm{~N}\right)^{+}\left(\mathrm{NO}_{3}\right)^{-}$. J Mol Struct 1164:486-492. https://doi.org/10.1016/j.molst ruc.2018.03.068

56. Al-Ahmary KM, Habeeb MM, Aljahdali SH (2019) Synthesis, spectroscopic studies and DFT/TD-DFT/PCM calculations of molecular structure, spectroscopic characterization and NBO of charge transfer complex between 5-amino-1,3-dimethylpyrazole (5-ADMP) with chloranilic acid (CLA) in different solvents. J Mol Liq 277:453-470. https://doi.org/10.1016/j.molliq.2018.12.072

57. Shahabi D, Tavakol H (2017) DFT, NBO and molecular docking studies of the adsorption of fluoxetine into and on the surface of simple and sulfur-doped carbon nanotubes. Appl Surf Sci 420:267-275. https://doi.org/10.1016/j.apsusc.2017.05.068

58. Venkat Rao C et al (2018) Vibrational and UV/Vis spectroscopic, NBO analysis of 1-(3-methylthiophen-2-yl)ethanone by ab initio DFT calculations. Mater Today Proc 5(13, Part 1):26430-26439. https://doi.org/10.1016/j.matpr.2018.08.097

Publisher's Note Springer Nature remains neutral with regard to jurisdictional claims in published maps and institutional affiliations. 